\title{
Long-term Outcome after Robotic-assisted Gastroplication in Adolescents: Hunger Hormone and Food Preference Changes Two Case Reports
}

\author{
Valeria Calcaterra1,* , Hellas Cena2,* , Maria Luisa Fonte2, Mara De Amici3, Matteo Vandoni4, \\ Michela Albanesi1, Gloria Pelizzo5
}

\author{
${ }^{1}$ Fondazione IRCCS Policlinico San Matteo, University of Pavia and Department of Maternal and Children's Health, Department of Internal Medicine, \\ Pediatric Unit, Pavia, Italy \\ 2 University of Pavia, Department of Public Health, Neurosciences, Experimental and Forensic Medicine, Section of Human Nutrition, Pavia, Italy \\ ${ }^{3}$ Fondazione IRCCS Policlinico San Matteo, Immuno-Allergy Laboratory, Clinic of Pediatric, Pavia, Italy \\ 4 University of Pavia, Department of Public Health and Neuroscience, Pavia, Italy \\ 5 Fondazione IRCCS Policlinico San Matteo and University of Pavia, Department of Maternal and Children's Health, Pediatric Surgery Unit, Pavia, Italy \\ ${ }^{*}$ Equal contribution
}

\section{WHAT IS ALREADY KNOWN ON THIS TOPIC?}

Weight loss surgery is efficacious for long-term weight reduction and decreases overall mortality in severely obese patients. The mechanisms implicated in long-term weight loss are not fully understood. Changes in gut hormones and brain regulation of appetite and satiety are proposed.

\section{WHAT THIS STUDY ADDS?}

We reported long-term follow-up after gastroplication in two adolescents. Weight loss is associated to a favorable change in hunger hormone and food preferences. Hormonal and sensory components in the long-term results seems to be crucial.

\section{ABSTRACT}

Weight loss surgery (WLS) is efficacious for long-term weight reduction and decreases overall mortality in severely obese patients. The mechanisms implicated in long-term weight loss are not fully understood. Proposed mechanisms include changes in gut hormones and brain regulation of appetite and satiety. We aimed to investigate the long-term ghrelin and leptin profiles and changes in food preference and eating behavior after WLS in adolescent patients. Two obese females aged 15 years and 14 $4 / 12$ years, who did not respond to lifestyle changes, including dietary intervention and physical exercise in combination with medical therapy, underwent roboticassisted gastroplication. Anthropometric measurements, food habits and eating behavior, as well as metabolic and hormonal changes during long-term post-surgical follow-up were monitored. Long-term weight reduction was obtained in both patients, with a significant decrease in waist circumference. Resting energy expenditure showed a decrease over time, with a respiratory quotient that increased showing a shift from oxidation of a high-fat diet before surgery to oxidation of a mixed diet two and three years later. Both subjects improved their eating habits and lifestyle. Comorbidity resolution was also noted. Increased pre-prandial ghrelin levels as well as higher post-prandial ghrelin and a leptin drop compared with pre-surgery values were observed in both patients. Persistent weight loss after gastroplication is associated with a favorable change in gut hormones and food preferences. The role of hormonal and sensory components in long-term results seems crucial. Particularly in adolescent patients, a multidisciplinary approach and continuous nutritional care is mandatory for weight maintenance and consolidation of changes.

Keywords: Robotic surgery, gastroplication, ghrelin, leptin, adolescent, food choices, eating behavior

Conflict of interest: None declared

Received: 30.07 .2015

Accepted: 30.10 .2015

Address for Correspondence

Gloria Pelizzo MD, Fondazione IRCCS Policlinico San Matteo and University of Pavia, Department of Maternal and Children's Health, Pediatric Surgery Unit, Pavia, Italy Phone: +390382502930 E-mail: g.pelizzo@smatteo.pv.it

OJournal of Clinical Research in Pediatric Endocrinology, Published by Galenos Publishing. 


\section{Introduction}

Weight loss surgery (WLS) is efficacious for long-term weight reduction and decreases overall mortality in severely obese patients $(1,2,3,4)$. The effect of WLS is probably not only due to restriction of food intake and/or malabsorption of ingested food, however, the mechanisms implicated in long-term weight loss are not fully understood. Proposed mechanisms include changes in gut hormones and brain regulation of appetite and satiety $(5,6,7)$. Hormones such as ghrelin, leptin, peptide $Y Y$ (PYY), glucagon-like peptide-1 (GLP-1), and cholecystokinin (CCK), secreted by the gastrointestinal (Gl) tract, the pancreas, and by the adipose tissue, are released into the periphery in response to increased or decreased intake of nutrients and are able to act peripherally on the vagus nerve and centrally on target areas in the hypothalamus $(8,9)$. In addition, crosstalk between the adipose tissue and the gut may also be relevant in the context of regulating energy homeostasis, satiety, and body weight. Leptin is released continuously from the adipose tissue into the circulation and acts mainly on the hypothalamus, regulating the long-term energy storage. In addition, exocrinesecreted gastric leptin is proposed to ensure proper food processing and food intake in the short term independently of adipose-derived leptin (10).

Modifications in the perception of food and hence eating behavior changes are also considered crucial in weight loss with long-term maintenance. Patients after WLS, particularly post Roux-En-Y Gastric Bypass (RYGB), report feeling less hungry, reaching satiety earlier, thus reporting a change in their taste and food choices. These changes have been strongly attributed to variations in taste processes and food reward $(11,12,13)$. Reports on neuro-hormonal assessment and shifts in food habits after WLS of subjects in the pediatric age group are scarce $(14,15)$.

In this paper, we report long-term ghrelin and leptin profiles and changes in food choices and eating behavior after roboticassisted gastroplication in two adolescent patients.

\section{Case Reports}

Two adolescents, who did not respond to lifestyle changes, including dietary intervention and physical exercise in combination with medical therapy, underwent robotic-assisted gastroplication.

Patient 1, a 15-year-old obese female with a body mass index (BMI) of $38.8 \mathrm{~kg} / \mathrm{m}^{2}$, was submitted to an eighteen-month organized and supervised lifestyle modification intervention, including family involvement and medical treatment 6 months of metformin) with no significant improvement. She had developed hyperinsulinism, hyperandrogenism, amenorrhea, ultrasound signs of Polycystic ovarian syndrome (PCOS), and hypertension with left ventricular hypertrophy.
Patient 2, a 14-year, 4-month-old obese female with a BMI of $41.2 \mathrm{~kg} / \mathrm{m}^{2}$, had an unsuccessful outcome after 20 months of supervised lifestyle changes, including family involvement. She was noncompliant with the medical treatment prescribed (metformin). Hyperinsulinism, dyslipidemia, moderate hepatic steatosis, gastroesophageal reflux (GER), obstructive sleep apnea (OSA) were reported before surgery.

Both girls had attained skeletal and developmental maturity (final height and pubertal stage) before the surgical treatment. No major contraindications for WLS were found, including eating disorders and psychopathologies. A multidisciplinary intervention with specific nutritional, psychological, and training sessions was started two months before surgery and continued post-surgery. Both girls were prescribed moderate-low energy diets balanced in macro- and micronutrients according to our national recommendations specific for age and sex (16) and were invited to weekly nutrition education sessions intended to be informative and interactive. For both patients, the capability to commit to comprehensive medical and psychological evaluation before and after surgery as well as patient and family willingness to participate in a postoperative multidisciplinary treatment program were documented. Written informed consent was obtained prior to enrollment. Gastroplication was performed using the Robotic surgery Da Vinci system ${ }^{\circledR}$ (Intuitive Surgical, Inc., Sunnyvale, California, USA) with an 8.5 $\mathrm{mm}$ scope and two 5-mm operative trocars. Two rows of nonabsorbable interrupted sutures (2-0 Ethibond ${ }^{\mathrm{TM}}$ ) were placed along the greater dissected curvature starting $1 \mathrm{~cm}$ below the angle of His, narrowing the stomach (80-100 mL of volume). No intra- or postoperative complications occurred. Pain control medication was only necessary for 2 days postoperatively and then stopped. The hospital stay lasted 96 hours. Proton pump inhibitors and anticoagulation were prescribed for 14 days.

During follow-up, metabolic and hormonal changes were documented. A complete nutritional assessment with anthropometric measurements, bioimpedance analysis, and indirect calorimetry $(\mathrm{IC})$ was performed under standard conditions: overnight fasting, abstaining from caffeine, alcohol, nicotine, and strenuous physical activity starting the day before, as abstaining from moderate physical activity for at least 2 hours $(17,18)$.

Food intake and eating habits were documented by the subjects keeping a daily food diary and a validated selfadministered food frequency questionnaire $(19,20)$ starting two months before surgery (TO) and repeated yearly post treatment.

Ghrelin and leptin were evaluated, before and after surgery, using a commercial enzyme immunometric assay (Human Unacylated Ghrelin, BioVendor R\&D, Brno, Czech Republic) and an enzyme-linked immunosorbent assay kit (Human Leptin Immunoassay, R\&D Systems, Minneapolis, MN) respectively, following the manufacturer's instructions. The results were expressed as pg/mL. 
Calcaterra $\mathrm{V}$ et al.

Long-Term Outcome after Gastroplication

The study was performed according to the Declaration of Helsinki. The Ethics Committee of the Fondazione IRCCS Policlinico San Matteo and Department of Internal Medicine, University of Pavia, approved the study protocol. All procedures were carried out with adequate understanding and written consent of the patients and their parents.

Nutritional assessment as well as metabolic and hormonal changes during long-term post-surgical follow-up are reported in Tables 1, 2, 3.

\section{Anthropometric Measurements and Food Habits and Eating} Behavior

Long-term weight reduction was obtained in both patients with a significant decrease in waist circumference (Table 1). Resting energy expenditure (REE) measured by IC also showed a significant decrease over time, with a respiratory quotient $(\mathrm{RQ})$ that increased, showing a shift from oxidation of a high-fat diet before surgery to oxidation of a mixed diet two and three years later.

Coupling the measurement of body composition to that of REE expands the diagnostic potential of IC (18). Once the lean and fat compartments had been measured by bioelectrical impedance analysis, it was possible to establish on the basis of REE whether the two subjects were becoming hyper- or hypometabolic. The results show, as expected, a slight decrease in metabolic efficiency during the first period (1 year after surgery) and values similar to initial ones despite weight loss during the following recovery period (Table 1).

Table 2 reports the main changes after WLS for food consumption, eating behavior, and lifestyle behavior.

\begin{tabular}{|c|c|c|c|c|c|c|c|c|}
\hline & \multicolumn{4}{|l|}{ Patient 1} & \multicolumn{4}{|l|}{ Patient 2} \\
\hline & $\begin{array}{l}\text { Before } \\
\text { surgery }\end{array}$ & $\begin{array}{l}1 \text { year after } \\
\text { surgery }\end{array}$ & $\begin{array}{l}2 \text { years after } \\
\text { surgery }\end{array}$ & $\begin{array}{l}3 \text { years after } \\
\text { surgery }\end{array}$ & $\begin{array}{l}\text { Before } \\
\text { surgery }\end{array}$ & $\begin{array}{l}1 \text { year after } \\
\text { surgery }\end{array}$ & $\begin{array}{l}2 \text { years after } \\
\text { surgery }\end{array}$ & $\begin{array}{l}3 \text { years after } \\
\text { surgery }\end{array}$ \\
\hline Social isolation & Yes & No & No & No & Yes & No & No & No \\
\hline $\mathrm{BMI} \mathrm{kg/ \textrm {m } ^ { 2 }}$ & 42.2 & 34.6 & 26.9 & 29.3 & 41.2 & 38.3 & 34.4 & 34.2 \\
\hline$W C \mathrm{~cm}$ & 122 & 98 & 94 & 92 & 123 & 108.5 & 105 & 105 \\
\hline $\mathrm{PA}^{\circ}$ & 5.5 & 5.7 & 4.8 & 5.0 & 5.7 & 6.0 & 5.7 & 5.6 \\
\hline FM kg $(\%)$ & $53.6(42.4)$ & $36.6(34.9)$ & $32.4(40.2)$ & $36.6(41.7)$ & $44.2(43.6)$ & $38.9(41.4)$ & $34.3(40.6)$ & $44.2(49.9)$ \\
\hline IC (Kcal/day) & 2090 & 1544 & 1354 & 1347 & 2012 & 1761 & ND & 1641 \\
\hline $\mathrm{RO}\left(\mathrm{VCO}_{2} / \mathrm{VO}_{2}\right)$ & 0.79 & 0.72 & 0.82 & 0.8 & 0.84 & 0.73 & ND & 0.97 \\
\hline $\begin{array}{l}\text { REE/kg FFM } \\
\text { (kcal/ kg FFM) }\end{array}$ & 28.8 & 22.8 & 28 & 26.3 & 35 & 32 & ND & 33 \\
\hline Fasting insulin (microlU/mL) & 66 & 13 & 7.8 & 4.3 & 36.1 & 19.7 & 14.1 & 10.2 \\
\hline Fasting blood glucose $(\mathrm{mg} / \mathrm{dL})$ & 90 & 77 & 77 & 73 & 92 & 88 & 80 & 83 \\
\hline HOMA-IR & 14.7 & 2.4 & 1.5 & 0.8 & 8.2 & 4.2 & 2.8 & 2.1 \\
\hline $\mathrm{HbA1C}$ & 5.6 & 5.1 & 5.1 & 5 & 5.9 & 5.5 & 5.4 & 5.4 \\
\hline Total cholesterol (mg/dL) & 149 & 134 & 157 & 160 & 207 & 192 & 172 & 179 \\
\hline HDL-cholesterol (mg/dL) & 53 & 48 & 67 & 73 & 34 & 37 & 32 & 45 \\
\hline Triglycerides (mg/dL) & 55 & 70 & 63 & 41 & 96 & 82 & 79 & 60 \\
\hline \multicolumn{9}{|l|}{ Ghrelin $(\mathrm{pg} / \mathrm{mL})^{*}$} \\
\hline - Pre-prandial & 38.23 & 75.54 & 127.68 & 57.35 & 21.14 & 76.68 & 110.13 & 42.97 \\
\hline - Post-prandial & 28.28 & 68.83 & 62.04 & 21.11 & 18.50 & 43.38 & 53.88 & 20.37 \\
\hline \multicolumn{9}{|l|}{ Leptin $(p g / m L))^{* *}$} \\
\hline - Pre-prandial & 8121 & 13265 & 26321 & 14610 & 56312 & 32497 & 18391 & 23487 \\
\hline - Post-prandial & 10508 & 20850 & 33264 & 26389 & 58200 & 64414 & 52353 & 39950 \\
\hline \multicolumn{9}{|c|}{$\begin{array}{l}\text { BMI: body mass index, WC: waist circumference, PA: phase angle value, FM: fat mass estimated by bioelectrical analysis, IC: indirect calorimetry, RQ: respiratory quotient, } \\
\text { REE/kg FFM: resting energy expenditure per kg of fat-free mass estimated by bioelectrical impedance analysis, HDL: high density lipoprotein, HOMA-IR: homeostatic model } \\
\text { assessment-insulin resistance, ND: not determined } \\
{ }^{*} \text { Ghrelin normal values: } 98-389 \mathrm{pg} / \mathrm{mL} \\
\text { **Leptin normal values: } 3877-77273 \mathrm{pg} / \mathrm{mL}\end{array}$} \\
\hline
\end{tabular}


Both subjects improved their eating habits and changed their lifestyle behavior (Table 1).

Dietary intake was assessed using a prospective 7-day food diary. Total energy intake ( $\mathrm{kcal} /$ day) was estimated based on the food diary and showed, though not equal, significant reductions in both subjects. Major changes were evident in particular the intake of proteins, compared to baseline (before surgery). Lipid and carbohydrate intake changed until reaching the national reference recommended dietary intake (16). Alternatively, fiber intake slowly increased by a more than expected rate, over the years (Table 3 ).

\section{Metabolic Changes and Co-Morbidities}

Patient 1 had a significant reduction in blood insulin level and a decrease in homeostatic model assessment-insulin resistance (Table 1). Resolution of hormonal and ultrasonographic features of PCOS was observed, and the girl regained normal menstrual cycles 5 months after surgery. Blood pressure also decreased to normal levels.
Patient 2 showed resolution of insulin resistance, of dysfunctional lipid metabolism and RGE (Table 1). Improvement in steatosis and OSA were also reported.

Improved social and emotional well-being and self-esteem were reported in both girls.

\section{Ghrelin and Leptin Profile}

Increased pre-prandial ghrelin levels were observed in both patients as well as a higher post-prandial ghrelin drop and leptin increase compared with pre-operative levels (Table 1, Figure 1).

\section{Discussion}

Recent evidence highlighting the prevalence of severe obesity in the pediatric population, coupled with disappointing outcomes related to medical weight loss interventions, has led to increased interest in WLS $(2,3,4)$. It is reported that the number of surgeries being performed in adolescents has increased 5-fold from 1997

Table 2. Lifestyle and food habits of the two patients, before and after surgery

\begin{tabular}{|c|c|c|c|c|c|c|c|c|}
\hline & \multicolumn{4}{|l|}{ Patient 1} & \multicolumn{4}{|l|}{ Patient 2} \\
\hline & $\begin{array}{l}\text { Before } \\
\text { surgery }\end{array}$ & $\begin{array}{l}1 \text { year after } \\
\text { surgery }\end{array}$ & $\begin{array}{l}2 \text { years after } \\
\text { surgery }\end{array}$ & $\begin{array}{l}3 \text { years after } \\
\text { surgery }\end{array}$ & $\begin{array}{l}\text { Before } \\
\text { surgery }\end{array}$ & $\begin{array}{l}1 \text { year after } \\
\text { surgery }\end{array}$ & $\begin{array}{l}2 \text { years after } \\
\text { surgery }\end{array}$ & $\begin{array}{l}3 \text { years after } \\
\text { surgery }\end{array}$ \\
\hline Number of meals/day & 4 & 4 & 5 & 5 & 3 & 5 & 4 & 4 \\
\hline Breakfast & No & Yes & Yes & Yes & No & Yes & Yes & Yes \\
\hline Food avoidance & Yes & No & No & No & Yes & No & No & No \\
\hline Portion size* & Medium & Small & Small & Medium & Big & Medium & Medium & Medium \\
\hline $\begin{array}{l}\text { Fruit and vegetable } \\
\text { portions/day }\end{array}$ & 3 & 3 & 2 & 2 & 0 & 2 & 2 & 2 \\
\hline $\begin{array}{l}\text { Soft drinks or junk food } \\
\text { consumption }\end{array}$ & Everyday & 0 & $\begin{array}{l}0-1 \text { time } \\
\text { per week }\end{array}$ & $\begin{array}{l}\text { 1-2 times } \\
\text { per week }\end{array}$ & Everyday & Never & Never & $\begin{array}{l}\text { 0-1 time } \\
\text { per week }\end{array}$ \\
\hline Physical activity & None & $\begin{array}{l}3 \text { times } \\
\text { per week }\end{array}$ & $\begin{array}{l}2 \text { times } \\
\text { per week }\end{array}$ & None & None & $\begin{array}{l}2 \text { times } \\
\text { per week }\end{array}$ & None & $\begin{array}{l}3 \text { times } \\
\text { per week }\end{array}$ \\
\hline
\end{tabular}

Table 3. Daily energy intake and diet composition of the two patients during long-term post-surgical follow-up

\begin{tabular}{|c|c|c|c|c|c|c|c|c|}
\hline & \multicolumn{4}{|l|}{ Patient 1} & \multicolumn{4}{|c|}{ Patient 2} \\
\hline & $\begin{array}{l}\text { Before } \\
\text { surgery }\end{array}$ & $\begin{array}{l}1 \text { year after } \\
\text { surgery }\end{array}$ & $\begin{array}{l}2 \text { years after } \\
\text { surgery }\end{array}$ & $\begin{array}{l}3 \text { years after } \\
\text { surgery }\end{array}$ & $\begin{array}{l}\text { Before } \\
\text { surgery }\end{array}$ & $\begin{array}{l}1 \text { year after } \\
\text { surgery }\end{array}$ & $\begin{array}{l}2 \text { years after } \\
\text { surgery }\end{array}$ & $\begin{array}{l}3 \text { years after } \\
\text { surgery }\end{array}$ \\
\hline Energy intake (kcal/day) & 3000 & 1300 & 1000 & 1150 & 2200 & 1400 & 1800 & 1900 \\
\hline \multicolumn{9}{|l|}{ Diet composition } \\
\hline Proteins $\%(g)$ & $18(134)$ & $21(69)$ & $20(49)$ & $14(41)$ & $16(91)$ & $19(68)$ & $15(68)$ & $13(64)$ \\
\hline Lipids \% & 43 & 40 & 29 & 23 & 27 & 34 & 29 & 32 \\
\hline Saturated fats $\%$ & 16 & 13 & 10 & 8 & 9 & 11 & 8 & 9 \\
\hline Carbohydrates \% & 39 & 39 & 52 & 63 & 57 & 47 & 56 & 50 \\
\hline Simple sugars $\%$ & 18 & 10 & 12 & 16 & 18 & 12 & 11 & 11 \\
\hline Fiber $(g)$ & 24 & 16 & 12 & 20 & 14 & 10 & 17 & 18 \\
\hline
\end{tabular}




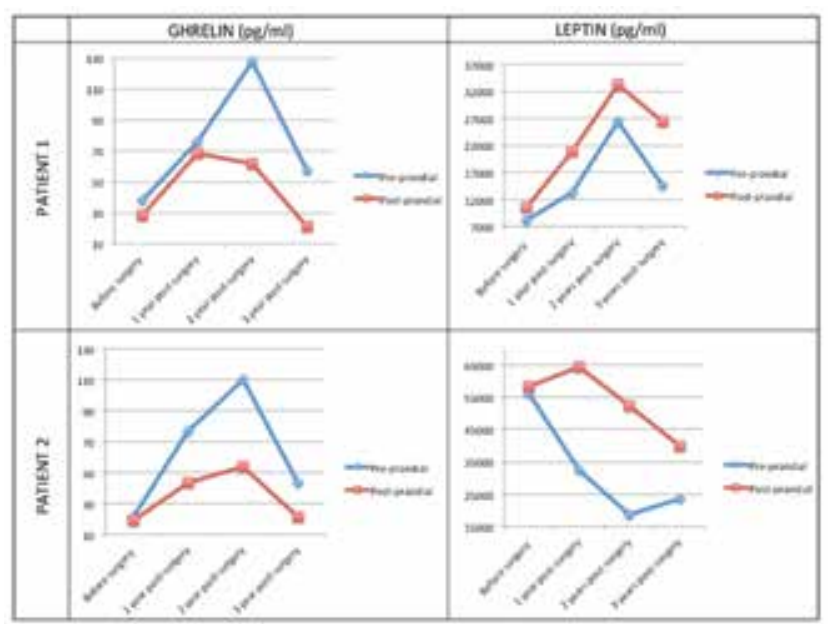

Figure 1. Ghrelin and leptin profiles of the two patients, before surgery and during long-term post-surgical follow-up

to 2003 and tripled in 2000-2003. The number of procedures performed yearly is rising, and WLS is currently the most effective treatment for morbid obesity and improvement of comorbidities in adolescents. While pharmacological and behavioral treatments are usually associated with weight loss followed by weight regain, WLS provides weight loss for at least 15 years in obese patients $(2,3,4,16)$.

We describe long-term weight reduction associated with resolution of comorbidities and a relevant change in neuroendocrine profile and food preferences as well as eating behaviors in two adolescents, after robotic-assisted gastroplication. This surgical approach in adolescence has the added advantages of being reversible, not requiring the use of foreign materials, and conforming to the physiological development of the individual. The clinical, metabolic, and hormonal improvements observed following a long-term follow-up confirm the effectiveness of this technique in young patients.

Gut hormones such as ghrelin, PYY, GLP-1, pancreatic polypeptide, oxyntomodulin are implicated in the short-term regulation of ingestion and adiposity signals such as insulin and leptin are involved in long-term energy homeostasis $(8,10)$. Our data confirmed that modifications in the milieu of gut hormones is implicated in the sustained weight loss observed following WLS. After food is ingested, nutrients pass through the $\mathrm{Gl}$ tract, stimulating the release of a range of peptide hormones. In the context of their local, central, and peripheral actions, these hormones also mediate satiety.

Ghrelin is the only known orexigenic gut hormone and it is principally secreted from X/A-like cells within gastric oxyntic glands. Ghrelin mediates its orexigenic action via stimulation of neuropeptide $Y$ (NPY)/agouti-related peptide (AgRP), coexpressing neurons within the arcuate nucleus (ARC) of the hypothalamus. The brainstem and vagus nerve may also contribute to the effects of ghrelin on food intake.
Insulin is synthesized in the $\beta$ cells of the pancreas and is secreted rapidly after a meal, with well-characterized hypoglycemic effects. However, insulin also acts as an anorectic signal within the central nervous system (CNS); insulin receptors are widely expressed in the brain, particularly in hypothalamic nuclei, such as the ARC, dorsomedial nucleus (DMN), and paraventricular nucleus, which are involved in the control of food intake.

Leptin is predominantly secreted by adipocytes with circulating levels proportional to fat mass. It exerts its anorectic effect via the ARC, where both NPY/AgRP and pro-opiomelanocortin (POMC)/cocaine- and amphetamineregulated transcript (CART) neurons express leptin receptors. Leptin inhibits NPY/AgRP neurons and activates POMC/CART neurons, resulting in reduced food intake and increased energy expenditure $(8,10,21,22)$.

Obesity in children is associated with leptin and insulin resistance, manifested by reduced serum levels of ghrelin and increased leptin and insulin levels. Preprandial levels of circulating ghrelin rise, then fall rapidly in the postprandial period. Obese subjects show a less marked drop in plasma ghrelin after meal ingestion $(23,24,25)$.

In our girls, ghrelin, leptin, and insulin levels were abnormal before surgery and a pronounced change in orexigenic and anorectic hormones was observed following WLS $(4,5,6,7)$. The analysis showed a significant post-prandial decrease in ghrelin and an increase in leptin levels compared with preoperative levels and confirmed the favorable impact of this surgical procedure on hunger hormonal changes. However, changes in hormones does not fully explain the magnitude of weight loss after WLS. Following WLS, body weight decreases, but body composition improves without relevant changes in the phase angle. It has been shown that phase angles are sensitive to differences in water distribution and can be used to predict \% body fat mass (26). The phase angle deviates little from initial values suggesting the maintenance of metabolically active mass. Besides, the phase angle is not just an indicator of adequate nutritional status preservation but more of an overall measure of function and general health (27). Further studies are necessary to show how phase angle differs between different populations, according to age, ethnicity, and body composition (27).

Both our patients improved their eating habits by eating fruits and vegetables which they never used to eat before surgery, although their fiber intake increased more slowly than expected over the years, highlighting the obstacle of adjusting to adequate consumption of fruits and vegetables, typical of teenager habits and food dislikes.

The patients also stopped skipping breakfast in the morning, increased the number of their meals per day decreasing the food portion size and avoided spontaneous soft drinks and junk food intake. Their diet improved with changes not only in energy intake but also in macronutrient composition with 
an impact not only on food choice and preference but also on metabolism with a better use of energy substrates reflected in a notable increase in $\mathrm{RQ}$ and metabolic efficiency $(18,28)$.

The mechanisms responsible for suppression of appetite and changes in food preferences are not well understood. Although a number of changes in food choice, taste functions, hedonic evaluation, motivation, and self-control have been documented in both humans and rodents after surgery, their importance and relative contribution to diminished appetite is still under investigation $(4,5,6,7)$. Hedonic and sensory components like olfactory and gustatory stimuli significantly affect the appetite and taste. Recent studies have increased our knowledge on the expression of receptors being targeted by metabolic hormones and peptides governing cellular processes underlying hunger (ghrelin, NPY) and satiety (insulin, leptin) in the olfactory mucosa, the olfactory bulb, and olfactory-related brain areas (29). This chemical nutritional information alters the olfactory message and adapts the function of the olfactory system. Obesityrelated changes influence the olfactory function (30). About one quarter of morbidly obese patients are hyposmic with significantly decreased discrimination and identification ability and limited gustatory function. The olfactory function can change metabolism and feeding-related behavior thus affecting the energy balance and body weight.

After laparoscopic WLS, the discrimination ability of the olfactory and gustatory functions improves (13). In our girls, no data on olfactory function were available. However, after gastroplication a shift in food preferences and development of food dislikes were observed supporting the sensory component role in long-term WLS outcomes.

It must be added that the inevitable changes due to the modifications in body weight, body shape, and body image perception create new stimuli that affect lifestyle changes and sociality.

Both of our two girl patients became more physically active and more engaging in their social relationships. Both showed a notable decrease in social isolation and reported an improvement in self-esteem and quality of life (3).

Major behavioral changes occur postoperatively. However, it is recommended to have a preoperative program to educate the subject on food choices, implement nutritional changes, and to prepare them for post-surgery modifications. The ultimate goal is to encourage the subjects to independently choose a healthier diet, which involves long-term preparation. In our patients, a very satisfactory post-operative weight loss was reported in the first and second year of follow-up, while a steady state in BMI as well as some other parameters from the second year to the third year were observed. A moderate decrease in the patients' compliance may have contributed to this trend. The surgical procedure is only one part of the treatment plan if the goal is to obtain effective and long-lasting results leading to persistent changes.
Substantial nutrition guidance is required before and after the surgical procedure. A multidisciplinary continuous approach is required to support these patients, helping them to change their food habits, meet their protein and fluid requirements, increase their physical activity, and learn to listen to their bodies recognizing the signals for hunger and satiety. Post-surgery weight loss and food choices can be monitored by a registered dietitian or a nutritionist, while the clinician may assess the state of health and well-being and also monitor the hormonal changes. In the follow-up, micronutrients should also be evaluated and specific supplementation should be prescribed if necessary.

In conclusion, the findings in our two patients show that persistent weight loss after gastroplication is associated with a favorable change in gut hormones as well as in food preferences, eating behavior, and lifestyle. The role of hormonal and sensory components in the long-term WLS results seems crucial. We should also emphasize the need for a multidisciplinary approach and continuous nutritional education in the long-term weight maintenance and consolidation of changes, particularly in adolescent patients.

\section{Acknowledgment}

The authors thank Dr. G. Nakib for surgical support, Dr. C. Torre and Dott. ssa S. Nigrisoli for technical support in the hormonal evaluation.

\section{Ethics}

Ethics Committee Approval: Fondazione IRCCS Policlinico San Matteo Committee (Approval number: 02-15-12), Informed Consent: It was taken.

Peer-review: External peer-reviewed.

\section{Authorship Contributions}

Concept: Gloria Pelizzo, Valeria Calcaterra, Hellas Cena, Design: Gloria Pelizzo, Valeria Calcaterra, Hellas Cena, Data Collection or Processing: Maria Luisa Fonte, Mara De Amici, Matteo Vandoni, Michela Albanesi, Analysis or Interpretation: Gloria Pelizzo, Valeria Calcaterra, Hellas Cena, Literature Search: Valeria Calcaterra, Hellas Cena, Writing: Gloria Pelizzo, Valeria Calcaterra, Hellas Cena.

Financial Disclosure: The authors declared that this study has received no financial support.

\section{References}

1. Buchwald $H$. The evolution of metabolic/bariatric surgery. Obes Surg 2014;24:1126-1135.

2. Beamish AJ, Johansson SE, Olbers T. Bariatric surgery in adolescents: what do we know so far? Scand J Surg 2015;104:24-32.

3. Lindekilde N, Gladstone BP, Lübeck M, Nielsen J, Clausen L, Vach $W$, Jones $A$. The impact of bariatric surgery on quality of life: a systematic review and meta-analysis. Obes Rev 2015;16:639-651. Epub 2015 Jun 11 
4. Thakkar RK, Michalsky MP. Update on bariatric surgery in adolescence. Curr Opin Pediatr 2015;27:370-376.

5. Dixon JB, Lambert EA, Lambert GW. Neuroendocrine adaptations to bariatric surgery. Mol Cell Endocrinol 2015;418:143-152. Epub 2015 Jun 1

6. Behary $P$, Miras AD. Food preferences and underlying mechanisms after bariatric surgery. Proc Nutr Soc 2015;74:419-425. Epub 2015 May 20

7. Hughes V. Weight-loss surgery: A gut-wrenching question. Nature 2014;511:282-284.

8. Marić G, Gazibara T, Zaletel I, Labudović Borović M, Tomanović $\mathrm{N}$, Ćirić $\mathrm{M}$, Puškaš N. The role of gut hormones in appetite regulation (review). Acta Physiol Hung 2014;101:395-407.

9. Parker HE, Gribble FM, Reimann F. The role of gut endocrine cells in control of metabolism and appetite. Exp Physiol 2014;99:1116-1120.

10. Camilleri M. Peripheral mechanisms in appetite regulation. Gastroenterology 2015;148:1219-1233. Epub 2014 Sep 21

11. Pepino MY, Bradley D, Eagon JC, Sullivan S, Abumrad NA, Klein S. Changes in taste perception and eating behavior after bariatric surgery-induced weight loss in women. Obesity (Silver Spring) 2014;22:13-20. Epub 2013 Dec 6

12. Le Roux CW, Bueter M. The physiology of altered eating behaviour after Roux-en-Y gastric bypass. Exp Physiol 2014;99:1128-1132.

13. Holinski F, Menenakos C, Haber G, Olze H, Ordemann J. Olfactory and gustatory function after bariatric surgery. Obes Surg 2015;25:2314-2320.

14. Calcaterra V, Pelizzo G, Nakib G, Larizza D, Fonte ML, De Amici $M$, Cena $H$. Hunger hormone profile monitoring after gastroplication in an adolescent. Horm Res Paediatr 2013;80:213-216. Epub 2013 Aug 31

15. Xanthakos SA. Bariatric surgery for extreme adolescent obesity: indications, outcomes, and physiologic effects on the gut-brain axis. Pathophysiology 2008;15:135-146. Epub 2008 Jun 27

16. SINU-Società Italiana di Nutrizione Umana. LARN: Livelli di Assunzione di Riferimento di Nutrienti ed energia per la popolazione italiana. IV Revisione. SICS editori, Milano, 2014.

17. Compher C, Frankenfield D, Keim N, Roth-Yousey L; Evidence Analysis Working Group. Best practice methods to apply to measurement of resting metabolic rate in adults: a systematic review. J Am Diet Assoc 2006;106:881-903.
18. Rosado EL, Kaippert VC, Santiago de Brito R. Energy expenditure measured by indirect calorimetry in obesity. DOI: 10.5772/55605 http://dx.doi.org/10.5772/55605 Accessed 15th June 2015.

19. Turconi G, Celsa M, Rezzani C, Biino G, Sartirana MA, Roggi C. Reliability of a dietary questionnaire on food habits, eating behaviour and nutritional knowledge of adolescents. Eur J Clin Nutr 2003:57:753-763.

20. Turconi G, Guarcello M, Berzolari FG, Carolei A, Bazzano R, Roggi C. An evaluation of a colour food photography atlas as a tool for quantifying food portion size in epidemiological dietary surveys. Eur J Clin Nutr 2005;59:923-931.

21. Pinkney $J$. The role of ghrelin in metabolic regulation. Curr Opin Clin Nutr Metab Care 2014;17:497-502.

22. Yu JH, Kim MS. Molecular mechanisms of appetite regulation. Diabetes Metab J 2012;36:391-398. Epub 2012 Dec 12

23. Gil-Campos M, Aguilera CM, Ramirez-Tortosa MC, Cañete R, Gil A. Fasting and postprandial relationships among plasma leptin, ghrelin, and insulin in prepubertal obese children. Clin Nutr 2010;29:54-59. Epub 2009 Jul 19

24. Stylianou C, Galli-Tsinopoulou A, Farmakiotis D, Rousso I, Karamouzis M, Koliakos G, Nousia-Arvanitakis S. Ghrelin and leptin levels in obese adolescents. Relationship with body fat and insulin resistance. Hormones 2007;6:295-303.

25. Reinehr T, de Sousa G, Roth CL. Obestatin and ghrelin levels in obese children and adolescents before and after reduction of overweight. Clin Endocrinol 2008;68:304-310. Epub 2007 Sep 14

26. Baumgartner RN, Chumlea WC, Roche AF. Bioelectric impedance phase angle and body composition. Am J Clin Nutr 1988;48:16-23.

27. Barbosa-Silva MC, Barros AJ, Wang J, Heymsfield SB, Pierson RN Jr. Bioelectrical impedance analysis: population reference values for phase angle by age and sex. Am J Clin Nutr 2005;82:49-52.

28. Westerterp KR. Food quotient, respiratory quotient, and energy balance. Am J Clin Nutr 1993;57(5 Suppl):759-764.

29. Palouzier-Paulignan $B$, Lacroix MC, Aimé P, Baly $C$, Caillol $M$, Congar $\mathrm{P}$, Julliard AK, Tucker K, Fadool DA. Olfaction under metabolic influences. Chem Senses 2012;37:769-797. Epub 2012 Jul 25

30. Overberg J, Hummel T, Krude H, Wiegand S. Differences in taste sensitivity between obese and non-obese children and adolescents. Arch Dis Child 2012;97:1048-1052. Epub 2012 Sep 20 